九州大学学術情報リポジトリ

Kyushu University Institutional Repository

\title{
Use of RSM Technology for the Optimization of Received Signal Strength for LTE Signals Under the Influence of Varying Atmospheric Conditions
}

Choudhary, Shilpa

Department of Electronics and Communication Engineering, G L Bajaj Institute of Technology and Management

Sharma, Abhishek

Department of Mechanical Engineering, G L Bajaj Institute of Technology and Management

Gupta, Shradha

Depertment of Applied Science and Humanities, G L Bajaj Institute of Technology and Management

Purohit, Hemant

Department of Electronics and Communication Engineering, Jodhpur Institute of Engineering and Technology

他

https://doi.org/10.5109/4150469

出版情報：Evergreen. 7 (4)，pp.500-509，2020-12. 九州大学グリーンテクノロジー研究教育センター バージョン：

権利関係 : 


\title{
Use of RSM Technology for the Optimization of Received Signal Strength for LTE Signals Under the Influence of Varying Atmospheric Conditions
}

\author{
Shilpa Choudhary ${ }^{1}$, Abhishek Sharma ${ }^{2}$, Shradha Gupta ${ }^{3}$, Hemant Purohit ${ }^{4}$, \\ Smriti Sachan ${ }^{5}$ \\ ${ }^{1,5}$ Department of Electronics and Communication Engineering, G L Bajaj Institute of Technology and \\ Management, Greater Noida, UP, India \\ ${ }^{2}$ Department of Mechanical Engineering, G L Bajaj Institute of Technology and Management, Greater \\ Noida, UP, India \\ ${ }^{3}$ Depertment of Applied Science and Humanities, G L Bajaj Institute of Technology and Management, \\ Greater Noida, UP, India \\ ${ }^{4}$ Department of Electronics and Communication Engineering, Jodhpur Institute of Engineering and \\ Technology, Jodhpur, Rajasthan, India \\ *Author to whom correspondence should be addressed: \\ E-mail: shilpadchoudhary@gmail.com
}

(Received August 10, 2020; Revised October 16, 2020; accepted November 15, 2020).

Graphical Abstract:

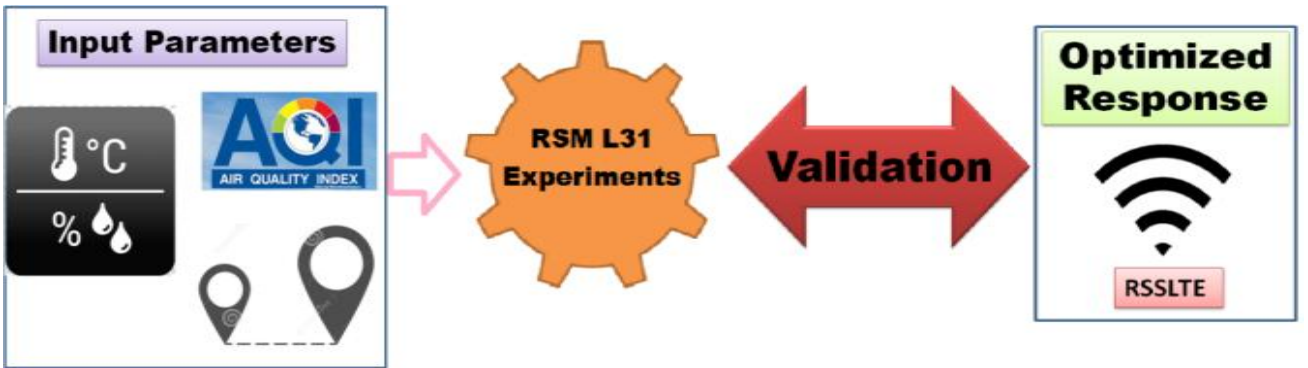

\begin{abstract}
In the field of telecommunication, network planning plays an important role to maximize the system performance and it is very much related to received signal strength (RSS). While transmitting signal from the transmitter to the receiver, signal has to face so many obstacles like varying environment conditions, high-rise buildings, dense forests etc. Signal strength gets affected with varying distance between the transmitter and receiver too. So for efficient network planning, information about the effect of all these parameters on received signal strength (RSS) should be known to us. So this study aimed to investigate the variation in Received Signal Strength for LTE signal (RSSLTE) with respect to the variation of four input parameters i.e. Relative humidity $(25 \%$ to $75 \%)$, Temperature $\left(12{ }^{\circ} \mathrm{C}\right.$ to $\left.48{ }^{\circ} \mathrm{C}\right)$, Air quality index for Particulate Matter 2.5 (50 to 500) and Distance from the base station ( $98 \mathrm{~m}$ to $300 \mathrm{~m}$ ). Optimization of received signal strength was also carried out by using response surface methodology. Optimum value of received Signal Strength for LTE signal (RSSLTE) was found to be $-87.0393 \mathrm{dBm}$ when the input parameters i.e. Temperature, Relative Humidity, Air Quality Index and Distance from Base Station were $13.10{ }^{\circ} \mathrm{C}, 31.30 \%, 52.10$ and $98 \mathrm{~m}$ respectively.
\end{abstract}

Keywords: Received signal strength; Response surface methodology; LTE; Optimization. 


\section{Introduction}

Among the wireless communication sector, mobile communication is the fastest growing application. Rapid increase of higher data rate applications has forced telecommunication department to enhance the mobile network capacity, coverage and access speeds. Wireless channel which carries the signal from transmitter to receiver is the most important part of wireless communication system because the channel conditions defines the received signal strength and this received signal strength is the key parameter which is being used for mobile network planning. While the transmission of these radio waves they have to cross the tropospheric layer of atmosphere and this layer is responsible for the refractivity of air. This refractivity may get change with changing atmospheric conditions like varying temperature, relative humidity etc. and which may affect the transmission of radio waves. While travelling through the channel radio waves may get absorbed, scattered, depolarized, and diffracted by many factors. Due to these phenomena's in propagation path, the received signal gets attenuated. This may result into reduced received signal strength. There are many other reasons which may affect the received signal strength like during the radio wave propagation through a long forested channel with mixed vegetation \& non-uniform density ${ }^{6)}$ can cause inter-channel interference which affects the received signal strength for mobile networks ${ }^{8)}$. Received signal strength is also susceptible to environmental dynamics such as varying temperature, relative humidity, atmospheric pressure, air quality index etc. Many propagation models have been proposed to obtain an estimation of signal strengths using empirical methods. These methods were used by mobile operators for planning and implementation of networks. These models are used to find suitability for prediction errors and standard deviations ${ }^{10)}$. For accurate and real-time system, research work is going on with Ray tracing methods developed for practical ray tracing algorithms. In the near future this Ray tracing will play a significant role to design the propagation modelling tools.

In view of all these constraints of propagation channel, an appropriate mathematical model is much required to mitigate the effect of various factors due to which the received signal strength for any wireless communication technology can get affected. This research work was mainly carried out to investigate the effect of four major parameters i.e. varying atmospheric temperature, relative humidity, air quality index and the distance from the base station on received signal strength of LTE technology and a proper mathematical model has been proposed and multi objective optimization have also been carried out by using response surface methodology.

\section{Related Work}

Much of the work have already been done to study the effect of environment factors as well as forested channel and dust particles on signal strength. Electromagnetic wave interaction with soil particles studied by G. Lo Sciuto $^{1)}$ to evaluate interaction between atmospheric particulate and EM-wave attenuation of radio signal at $2.4 \mathrm{GHz}$. They studied the variation of received signal level (RSL) with concentration of PM10. They used data transfer speed of $150 \mathrm{Mbit} / \mathrm{sec}$ for $2.4 \mathrm{GHz}$ and temperature and humidity not greater than $800{ }^{\circ} \mathrm{C}$ and $95 \%$ respectively and detected the concentration of particulate. They take the operating condition of low, medium and high concentration of PM10. From observation they concluded that RSL has no significant variation but RSL local variance has polynomial dependency. Attenuation of electromagnetic waves as travel through free space is studied by Danial Abdorahimi and Ali M. Sadeghioon ${ }^{2)}$ using Friis transmission equation and it is modified to consider the soil dielectric behavior and compared with another CRIM-Fresnel model. Signal attenuation was measured at $\mathrm{MHz}$ which showed variation of experimental result with these two models. The attenuation of radio signals with Strong wind speed and heavy rain were studied by Sharifah Nurul Aisyah Syed Zafar et al. ${ }^{3)}$ in the East Coast of Peninsular Malaysia. The results of this paper are useful for the drastic changes in weather. The correlation value and strength were obtained statistically between these factors in wet and dry seasons. The radio signal strength was measured using the Spectrum analyser and the wind speed $(\mathrm{km} / \mathrm{h})$ using weather station. Their result indicates that radio signal strength (RSS) is highly attenuated by strong winds \& high level of rain and humidity during the wet season. The Dry season increase the RSS and hence favorable for signal strength. AT $1835 \mathrm{MHz}$ frequency UHF radio wave propagates through a long-forested channel of $8 \mathrm{~km}$ with mixed vegetation \& non-uniform density. A. S. Adewumi and O. Olabisis ${ }^{4)}$ found the suitable model from existing models for long forested channel and deduce unique model from obtained data use in such case. But no model is suitable to predict UHF radio wave propagation through long non-homogeneous forest channel. Scattering and attenuation of signal through vegetation path been studied by N. R. Leonor et al. ${ }^{5)}$ using image theory and radiation path. The re-radiation measurements were conducted both at 20 and 64.5GHz system for all 16 conifer and 13 ficus benjamina trees. The comparison was carried out using discretized radiative energy transfer approach with the result of good agreement was found. Fachransjah Aliunir et al. ${ }^{7)}$ suggested that RSM technology can be used as the optimization tool with which optimization of system parameters can be done and that too with minimum number of experiments runs. The vegetation signal path of signal was studied in suburban and rural areas in Brazil by J. C. Silva et al. ${ }^{9)}$ to present pessimistic approach at the UHF frequency range of 700 to $800 \mathrm{MHz}$ The Weissberger model, The COST 235 model, the Chen and 
Kuo model were compared with the proposed model by using Signal (continuous tone) of frequencies of 700 $\mathrm{MHz}, 750 \mathrm{MHz}$ and $800 \mathrm{MHz}$ with constant power, receiver at 1.5 meters and transmitter at a height of $1.5,6$ and 12 meters. The measurements were taken at 20 different distances between the antennas. They concluded the similarity with Weissberger and Chen and Kuo models are evident, for greater distance between transmitter and receiver this model has significant differences with the existing ones. Measurements conducted by S. H. Suleiman et al. ${ }^{11)}$ using the outdoor RF signal measurement (consists of spectrum analyzer) and received signal power levels (RSSI) (using omnidirectional antenna) for Automated Meter Reading (AMR) system by mobile services operating in GSM900, GSM1800, UMTS and LTE frequency bands. They came with solutions of installing high gain antennas and signal boosters at selected places within the district. Path loss factor of signal strength was studied by Myo Z.M., Mon M.T. ${ }^{12)}$. They used the processor sharing queuing theory to analyse power loss during signal propagation over LTE network. Path loss by transmitter and receiver was calculated during signal propagation through air channel. Author taken the idealistic condition of uniform distribution over the cell zone and user was in still condition throughout the whole transmission. Their analysis was focused on path loss i.e. signal deviation in each zone. They used the expression for mean traffic load and arrival rate in each zone and calculated the average file downloading time to discuss the variations of mean file transfer time due to path loss. Adegboyega Gabriel Adisa $^{13)}$ studied the UHF signals strength variation with refractivity while taking observations during day and night at the location of Akure, South Western Nigeria in month of March 2013. They concluded that the refractivity is higher in the nights as compared to the days because of the high humidity and low temperature at nights, thus signal strength decreases in night as compare to day. E.P. Agbo et al. ${ }^{14)}$ studied experimentally quality of VHF, UHF and SHF and its dependency on refractive index variation with (Climate) temperature and (water) humidity. The temperature of atmosphere and its humidity changes throughout the year in every place and thus causes changes in quality of radio waves propagates through it. This was studied for 12 year monthly and its annual changes in refractive index due to temperature and humidity at the place of Calabar. They obtained an equation using linear regression and studies refractivity, relative humidity, atmospheric pressure variation monthly for every year. They found variation of refractive index of atmosphere with temperature and humidity. In same area observation were done by J. I. Iloke et al. ${ }^{15)}$ and found a linear relationship between water vapor pressure \& refractivity with $\mathrm{R}^{2}$ is 0.9902 . Relationship between refractivity \& temperature with $\mathrm{R}^{2}$ is 0.8442 , for 10 years (2010-2019) during rainy season. Fang and Y. S. Yang ${ }^{16)}$ studies the distance estimation for GSM signals for dry and wet atmospheric weather condition based on a typical rain attenuation model and a radio propagation model. They found that distance estimation significantly degraded under precipitation condition. A.I. Chima et al. ${ }^{17)}$ studied the effect on received signal strength for 5 month and found that considerable increase or decrease in temperature causes a significant change in the received signal whereas the wind speed has little impact on it. Joseph Amajama ${ }^{18)}$ had taken observation half hourly from the residence in Etta-agbor, Calabar to draw a justifiable inference on the impact of atmospheric parameters on signal strength (UHF). With the conclusion that temperature, atmospheric pressure and relative humidity were inversely proportional to the signal strength. J. Luomala and I. Hakala ${ }^{19)}$ work and studied the effects of temperature and humidity on radio signal strength in outdoor WSNs. They tried to link the variation of signal strength with temperature, relative humidity, and absolute humidity. Their experimental result during winter and summer season confirms the temporal variation of signal strength. They find negative correlation (dependence) between temperature and signal strength. They use the Pearson correlation coefficients and simple linear regression of relative humidity is statistically significant for both relative humidity and absolute humidity. S. Fang et al. ${ }^{20}$ proposes an enhanced received signal strength based distance estimator for prediction of precipitation by proposing an analytical expression for maximum likelihood- based distance estimation. They done experiments on mobile networks and sensed the RSS using smart phones. Their proposed distance estimation method achieves $85 \%$ to $90 \%$ error reduction rate. To study the effect of humidity F. Beritelli et al. ${ }^{21)}$ collected received signal values and created data base with collected data using power measurements in 4 different condition i.e. no-rainfall, weak rain, moderate rain and heavy rain. To classify and identify rainfall levels they used RSL features like RSL instantaneous, RSL average value and RSL variance. Then minimize the probability error of variance calculation using window size. After minimizing with respect to threshold \& window size, obtain sliding window size of 30 samples. By changing window size from 15 to 30 samples they classified 3 rainfall conditions. I. Shayea et al. $^{22)}$ investigate the impact of rain on the propagation of millimeter waves at $26 \mathrm{GHz}$ by using a microwave radio link system with $1.3 \mathrm{~km}$ path length at Johor Bahru, Malaysia. The system was implemented containing Ericsson CN500 mini E-link, radio unit, rain gauge, and data logger. Analysed and processed the annual rain rate and rain attenuation, including the worst month the measurements were attained and logged daily for a continuous year with one-minute time intervals. They came with the result that from worst month statistic obtained from the real measurements was lower than what was predicted by the ITU model; around $51 \%$ and $34 \%$ for the rain rate and rain attenuation, respectively. 
Ryan Imansyah ${ }^{23)}$ studied Impact of Internet Penetration for different wireless communication technologies on the economic growth of Indonesia. Dwivedi et al. ${ }^{24)}$, Sharma et al. $^{25)}$ and Choudhary et al. ${ }^{26)}$ suggested that RSM technology can be used as a multi-objective optimization tool. Karthik Vasudeva et al. ${ }^{27)}$ investigated the V2I connectivity performance of LTE deployments in rural, semi-urban and urban scenarios using extensive drive-test measurement campaign. The joint distributions of the link quality metrics are obtained, which indicate stronger coverage and higher BS density in urban and semi-urban compared to rural scenarios. Simultaneously they observed that shorter duration of network dis-connectivity and more handovers were observed in urban region as compared to semi-urban and rural region. They also observed that higher operating frequencies of LTE networks yield lower coverage. A. Akinbolati et al. ${ }^{28)}$ investigated the path losses of three Digital Terrestrial Television Base Stations (DTTBS) and calculated the path loss by using Okumura-Hata model. They observed that path loss increases with increasing distance between transmitter and receiver and also observed the high path loss in wet season compared to dry season.

From the literature review it is clear that so much work has already been done to investigate the effect of different environment factors on received signal strength for all the wireless communication technologies and also many path loss models have been proposed to mitigate the effect of environment factors which may hamper the received signal strength in mobile communication. But so far, optimization of these environmental factors has not been done in any research work to get the maximum received signal strength. So, keeping these factors in mind this research focused on experimental investigation and optimization of received signal strength for four input parameters i.e. varying temperature, relative humidity, air quality index and distance from base station. Optimization was carried out by using response surface methodology, which is a multi-objective optimization technique.

\section{Materials and Methods}

Flow chart of the research work is shown in fig. 1. In this research work, the variation in receives signal strength $(\mathrm{dBm})$ with respect to varying four input parameters i.e. Varying temperature $\left(12{ }^{\circ} \mathrm{C}\right.$ to $\left.48{ }^{\circ} \mathrm{C}\right)$, Relative humidity (25\% to $75 \%$ ), Air quality index for PM2.5 (50 to 500) and the distance from the base station $(98 \mathrm{~m}$ to $300 \mathrm{~m})$ were monitored for LTE wireless communication technology. All these observations were carried out from January 2019 to March 2020 at Lajpat Nagar (Densely populated residential area with high rise buildings), New Delhi. This area was considered for the observation so that the effect of deep shadow area can also be observed. Received signal strength (RSS) was measured with the help Spectrum Analyzer, distance from the base station was measured with the help of GPS system of mobile hand set and the open signal mobile application, Hygro-Thermometer was used to measure temperature and relative humidity and air quality index (A.Q Index) was measure by air quality index. Here the response surface methodology (RSM) was used for mathematical modeling and optimization. It is a multi-objective optimization technique. With the help of RSM approach, optimization can be done with minimum number of experiments runs. Different coding levels used for all the input parameters are as shown in Table 1.

Using these parameters experimental design developed through the statistical tool MINITAB 17. Experimental results obtained after implementing the CCRD are shown in Table 2. After the experiments as per the designed matrix, ANOVA was applied and good $\mathrm{R}^{2}$ correlation relation found between input and output responses.

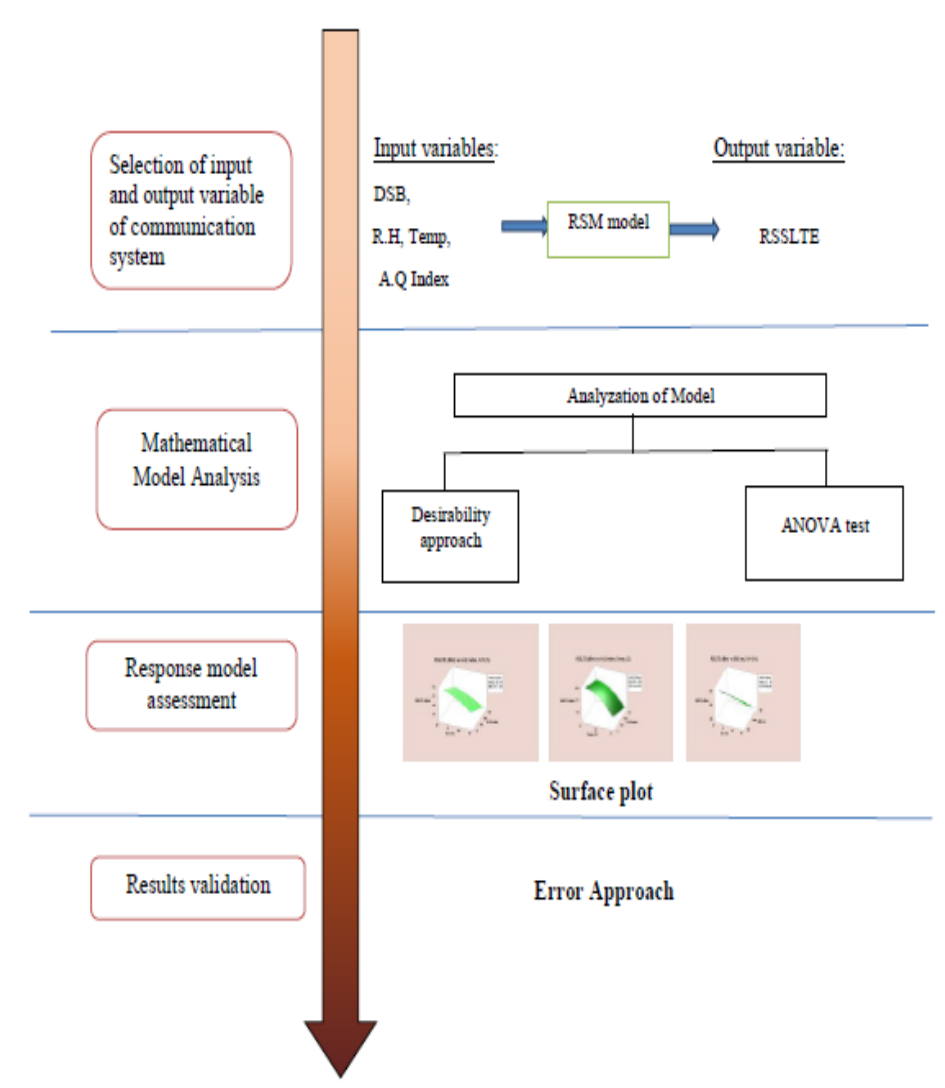

Fig. 1: Flow chart of research work

\subsection{RSM Technology}

To find the optimum solution, Response Surface Methodology (RSM) can be used. With the help of RSM modelling best values of output can be obtained for the optimum values of input variables. The main advantage of RSM is that it has predefined set of number of experiments runs for specific number of input variables and these numbers of experiment runs are very low as compared to other optimization techniques.

This study discussed the application of response surface methodology (RSM) and central composite rotatable 
design (CCRD) for modelling and optimization of the influence of some operating variables on the response. Four operating variables, namely atmospheric temperature (12-50) ${ }^{\circ} \mathrm{C}$, Relative humidity (25-75) \%, Distance from base station (98 - 300) $\mathrm{m}$ and Air quality index (98 -300) were changed during the tests based on CCRD.

\subsection{Experiment based on RSM}

This study was carries out for four input variables i.e. R.H (Relative Humidity), A.Q Index (Air Quality Index) for PM 2.5 particle, DBS (Distance from Base Station) and Temp (Temperature) and the effect of these input variables were observed on RSSLTE (Received Signal Strength for LTE Technology) as response. Considered range for the input variables is shown in Table 1 and Table 2 shows the experimental results obtained after the execution of CCRD.

Table 1. Experiment coding level

\begin{tabular}{|l|c|r|r|r|r|}
\hline \multirow{2}{*}{$\begin{array}{c}\text { Factors or input } \\
\text { parameters }\end{array}$} & \multicolumn{5}{|c|}{ Coded Levels } \\
\cline { 2 - 6 } & $\mathbf{- 2}$ & $\mathbf{- 1}$ & $\mathbf{0}$ & $\mathbf{1}$ & $\mathbf{2}$ \\
\hline Temperature $\left({ }^{\circ} \mathrm{C}\right)$ & 12 & 23 & 30 & 40 & 48 \\
\hline R.H (\%) & 25 & 37 & 50 & 63 & 75 \\
\hline DBS (m) & 98 & 150 & 200 & 250 & 300 \\
\hline A.Q Index & 50 & 150 & 250 & 370 & 500 \\
\hline
\end{tabular}

Table 2. Post CCRD experimental results

\begin{tabular}{|c|l|l|l|l|l|}
\hline $\begin{array}{c}\text { Exp. } \\
\text { Run }\end{array}$ & $\begin{array}{l}\text { Temp } \\
\left({ }^{\circ} \mathrm{C}\right)\end{array}$ & $\begin{array}{l}\text { R.H } \\
(\% \mathbf{R . H})\end{array}$ & DBS(m) & $\begin{array}{l}\text { A.Q } \\
\text { Index }\end{array}$ & $\begin{array}{l}\text { RSSLTE } \\
(\mathbf{d B m})\end{array}$ \\
\hline 1 & 40 & 63 & 250 & 370 & -123.6 \\
\hline 2 & 30 & 50 & 200 & 250 & -107 \\
\hline 3 & 30 & 50 & 200 & 250 & -107 \\
\hline 4 & 48 & 50 & 200 & 250 & -123 \\
\hline 5 & 40 & 37 & 150 & 370 & -116.55 \\
\hline 6 & 40 & 37 & 150 & 150 & -108.75 \\
\hline 7 & 40 & 63 & 150 & 370 & -120.15 \\
\hline 8 & 23 & 37 & 250 & 150 & -97.2 \\
\hline 9 & 40 & 37 & 150 & 150 & -108.75 \\
\hline 10 & 30 & 50 & 98 & 250 & -103.86 \\
\hline 11 & 30 & 50 & 200 & 250 & -107 \\
\hline 12 & 12 & 50 & 200 & 250 & -89 \\
\hline
\end{tabular}

\begin{tabular}{|c|c|c|c|c|c|}
\hline 13 & 23 & 63 & 250 & 150 & -100.8 \\
\hline 14 & 30 & 50 & 200 & 250 & -107 \\
\hline 15 & 30 & 50 & 300 & 250 & -110.9 \\
\hline 16 & 23 & 63 & 150 & 370 & -105.15 \\
\hline 17 & 40 & 63 & 250 & 150 & -115.8 \\
\hline 18 & 30 & 50 & 200 & 50 & -102.7 \\
\hline 19 & 40 & 63 & 150 & 150 & -112.35 \\
\hline 20 & 30 & 25 & 200 & 250 & -104 \\
\hline 21 & 30 & 75 & 200 & 250 & -111.5 \\
\hline 22 & 40 & 37 & 250 & 150 & -112.2 \\
\hline 23 & 30 & 50 & 200 & 250 & -107 \\
\hline 24 & 30 & 50 & 200 & 250 & -107 \\
\hline 25 & 23 & 37 & 250 & 370 & -105 \\
\hline 26 & 23 & 63 & 250 & 370 & -108.6 \\
\hline 27 & 40 & 37 & 250 & 370 & -120 \\
\hline 28 & 23 & 63 & 150 & 150 & -97.35 \\
\hline 29 & 30 & 50 & 200 & 250 & -107 \\
\hline 30 & 23 & 37 & 150 & 370 & -101.55 \\
\hline 31 & 30 & 50 & 200 & 500 & -119 \\
\hline
\end{tabular}

ANOVA was applied, which offers quantitative results about the p-value. The p-value is explained as the alternative to the rejection levels to provide the lowest level of worth at which the null hypothesis would be rejected. The highest level of $\mathrm{p}$ is taken as 0.05 and the values above than 0.05 are referred as an irrelevant. Empirical correlation for RSSLTE is shown by Equation 1.

$$
\begin{aligned}
\operatorname{SSLTE}(\mathrm{dBm})= & -60.04+0.155 * \operatorname{Temp}\left({ }^{\circ} \mathrm{C}\right)-0.109 \\
& * R H(\%)-0.2357 * D B S(m)-0.029 \\
& \left.* A . Q \text { Index }-0.0128 * \operatorname{Temp}{ }^{\circ}{ }^{\circ} \mathrm{C}\right) \\
& -0.00119 * R H^{2}(\%)+0.0001 \\
& * D B S^{2}(\mathrm{~m})+0.000003 * A . Q \text { Index }{ }^{2} \\
& +0.0008 * \operatorname{Temp}\left({ }^{\circ} \mathrm{C}\right) * R H+0.0003 \\
& * \operatorname{Temp}\left({ }^{\circ} \mathrm{C}\right) * D B S(m)+0.000093 \\
& * \operatorname{Temp}\left({ }^{\circ} \mathrm{C}\right) * A . Q \text { Index }+0.00012 \\
& * R H(\%) * D B S(m)+0.0006 * R H(\%) \\
& * \text { A. } Q \text { Index }+0.000019 * D B S(m) \\
& * \text { A. } Q \text { Index. }
\end{aligned}
$$

$\mathrm{R}^{2}$ and $\mathrm{R}^{2}$ (adj) values are $98.16 \%$ and $97.88 \%$, respectively for RSSLTE response and found satisfactory 
as it was above $95 \%$ for the sample.

In statistics, main effect plots show the effect of one of the independent variables on the RSSLTE response. There will always be the same number of main effects as independent variables. An interaction effect occurs if there is an interaction between the independent variables that affect the dependent variable. Fig. 2 shows the main effect plot for RSSLTE, all parameters have declined impact on RSSLTE with inputs.

Distance from station shows more impact on RSSLTE response. Relative humidity and air quality index have less impact on RSSLTE as compared to ambient temperature and distance from base station as seen in Fig. 2.

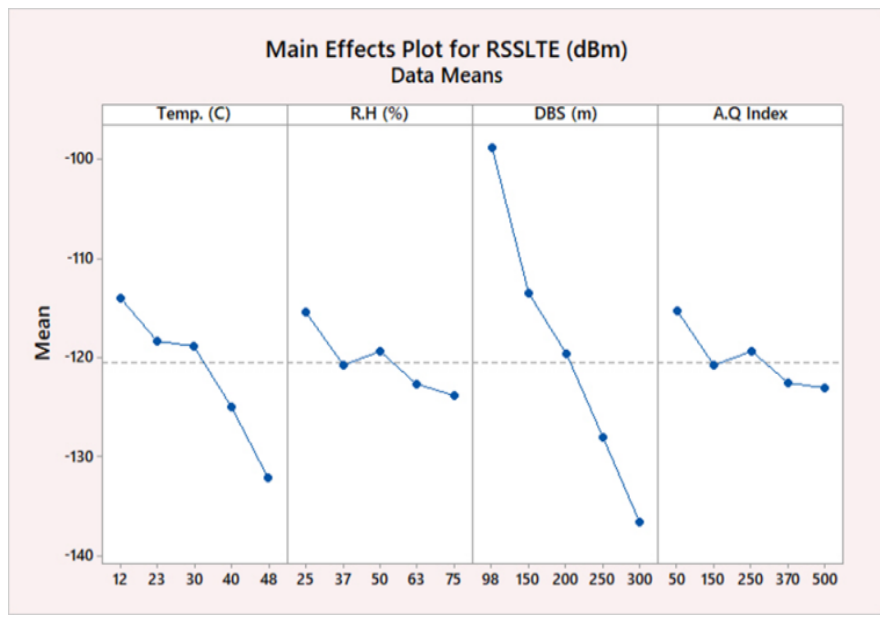

Fig. 2: Main effect plots for RSSLTE

\section{Result and Discussion}

With the help of MIMITAB17 software surface and Contour plots were obtained. In this research work, R.H (Relative Humidity), A.Q Index (Air Quality Index) for PM 2.5 particle, DBS (Distance from Base Station) and Temp (Temperature) were considered as input variables. All the plots were drawn only with respect to two input variables and at the same time other two input variables were kept at a constant or hold value and which is mentioned on the top right corner of each contour and surface plot. These hold values are the center value of each input variable which has shown in Table 1.

Fig. 3(a) is the surface plot which shows the variation in received Signal Strength for LTE technology (RSSLTE) with respect to two input parameters i.e. Relative Humidity (R.H) and Air Quality Index (A.Q Index) varying from $25 \%$ to $75 \%$ and from 50 to 500 respectively. At the same time the other two input parameters i.e. Temperature (Temp) and Distance from Base Station (DBS) were kept at hold value of $30^{\circ} \mathrm{C}$ and $200 \mathrm{~m}$ respectively. From Fig. 3(a) it can be observed that the RSSLTE keeps on decreasing with the increase in percentage R.H, it occurs because radio waves are form of electromagnetic waves so the characteristics of radio waves resembles with the light. When the light wave passes through the water molecule, it gets absorbed and the intensity of light decreases. The reason behind this is the collision with water molecule and the increase in air pressure. In the similar way humidity in atmosphere increase the air pressure and the number of water molecules in atmosphere and which weaken the transmission and results into reduced received signal strength. Also due to the presence of water molecule in the air, radio waves have to face scattering, diffraction and reflection and it results into reduced received signal strength. From the same Figure it can also be observed that the RSSLTE have same relation with A.Q Index but this variation is almost negligible.

Fig. 3(b) shows the contour plot for the surface plot shown in Fig. 3(a). From this Figure it is clear that RSSLTE will attain its maximum value of around -111.5 $\mathrm{dBm}$ when R.H and A.Q Index were $25 \%$ and 50 respectively and will be at its minimum value of -127 $\mathrm{dBm}$ when R.H and A.Q Index were $75 \%$ and 500 respectively.

Variation in RSSLTE with respect to varying Temperature (Temp) and Air Quality Index (A.Q Index) from $12{ }^{\circ} \mathrm{C}$ to $48{ }^{\circ} \mathrm{C}$ and 50 to 500 respectively can be observed in Fig. 3(c). At the same time remaining two input parameters i.e. Relative Humidity (R.H) and Distance from Base Station (DBS) were at hold value of $50 \%$ and $200 \mathrm{~m}$. This Figure shows that RSSLTE have sharp decrease with increasing TEMP where it decreases gradually with respect to A.Q Index (almost negligible). The reason for this decrement in RSSLTE with respect to increase inn TEMP is occurs because with the increase in temperature resistivity of the medium increases, which means the current and the power of the device get reduced for a particular voltage. So, with the increase in temperature the signal to noise ratio for a radio transceiver reduces and due to which received signal strength get reduced. Contour plot for all these parameters have been shown in Fig. 3(d). From Fig. 3(d) it can be observed that RSSLTE will attain its maximum and minimum value of approximately $-108 \mathrm{dBm}$ and $-135.2 \mathrm{dBm}$ respectively.

Fig. 3(e) and Fig. 3(f) shows the surface and contour plot from which the variation in RSSLTE can be observed when Relative Humidity (R.H) and Distance from base station (DBS) are varying from $25 \%$ to $75 \%$ and $98 \mathrm{~m}$ to $300 \mathrm{~m}$ respectively while keeping other two input parameters i.e. Temperature (Temp) and Air Quality Index (A.Q Index) at hold value of $30{ }^{\circ} \mathrm{C}$ and 250 respectively. Form these two plots it can be observed that RSSLTE decreases with increase in R.H as well as DBS it is because the radio wave intensity is inversely proportional to the square of distance between transmitter and receiver, which means the if the distance between the transmitter and receiver is doubled, the power received at the receiver will reduce four times. The contour plot shows that RSSLTE can attain its maximum value of around $-98 \mathrm{dBm}$ when the $\mathrm{RH}$ and DBS are at $25 \%$ and $98 \mathrm{~m}$ respectively. 


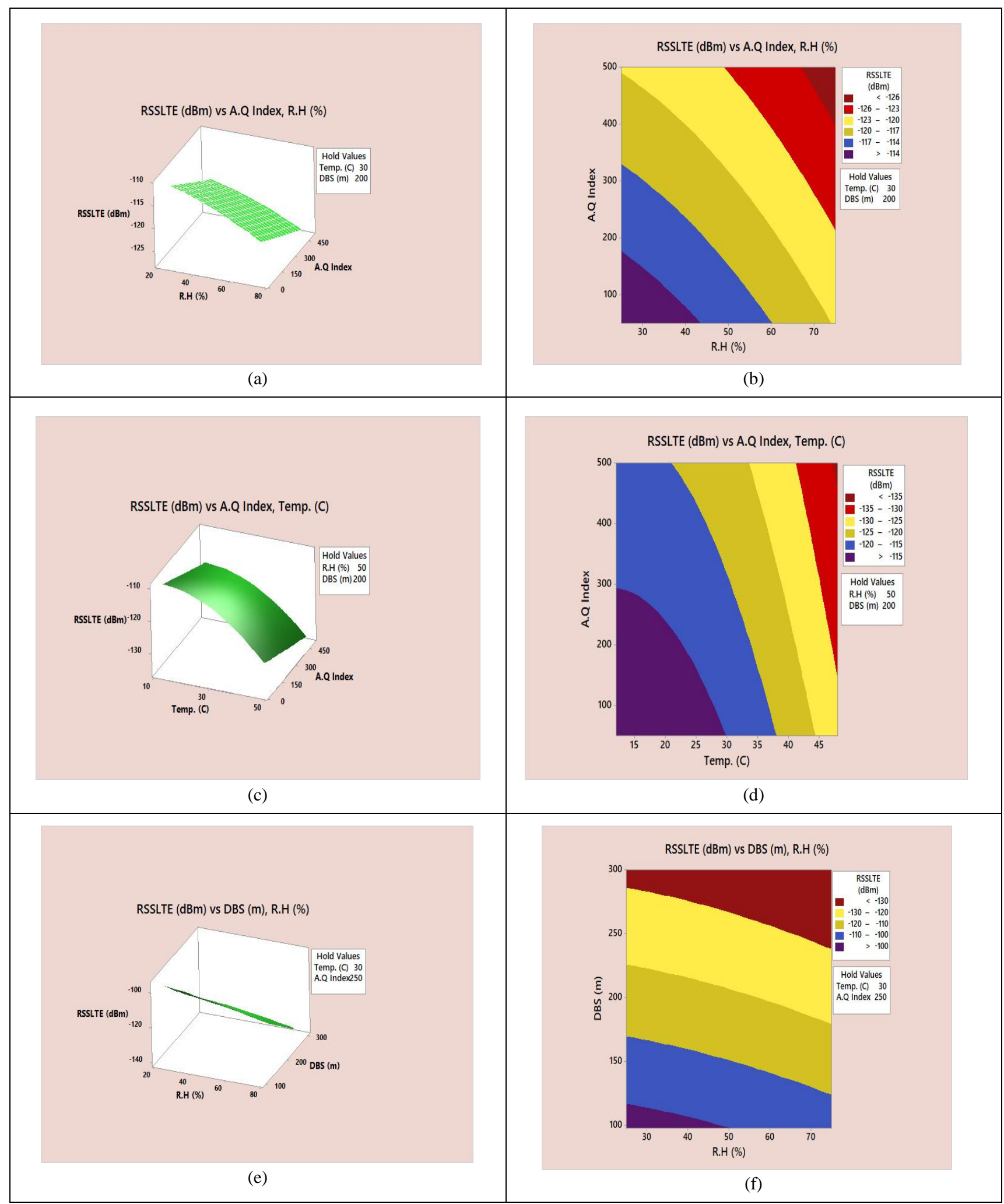

Fig. 3: Effect of environment parameters on received signal strength of LTE signal.

\section{RSM optimization response and validation}

RSM optimizer is shown in Fig. 4. With the help of RSM optimizer best possible value of response can be found out for the optimum values of input variables. The objective of this research work was to maximize the Received Signal Strength for LTE technology.

Optimum values of Temp (atmosphere temperature), R.H (Relative Humidity), A.Q Index - (Air Quality 
Index) for PM 2.5 and DBS (Distance from Base Station) were found to be $13.10{ }^{\circ} \mathrm{C}, 31.30 \%, 52.10$ and $98 \mathrm{~m}$ respectively. At above said input setting, optimum responses were found $-87.0393 \mathrm{dBm}$ for (Received Signal Strength for LTE- RSSLTE). Desirability for the response was found to be unity that is a good signal of process optimization for Received signal strength for LTE Technologies. To validate RSM results, experiment was carried out at $13^{\circ} \mathrm{C}$ ambient temperature, 98 meters distance from base station, $27 \%$ relative humidity and at air quality index (A.Q Index 55).

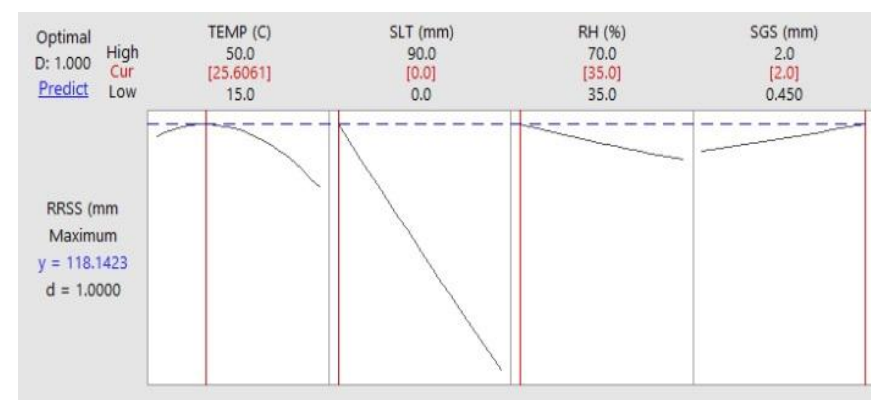

Fig. 4: Optimization plot: Effect of process parameters on responses.

The lab examination details are shown in Table 3 shows the response for RSSLTE. Experimental responses were compared with the RSM optimizer values.

Table 3. Validation of RSM results

Response at $13^{\circ} \mathrm{C}, 98 \mathrm{DBS}, 31.2 \%$ R.H, with $52 \mathrm{~A} . \mathrm{Q}$ Index

$\begin{array}{lrrr}\text { Response } & \text { Predicted } & \text { Actual } & \text { Error (\%) } \\ \text { RSSLTE } & -87.03 & -85.43 & 1.83 \\ (\mathbf{d B m}) & & & \end{array}$

The error percentage for RSSLTE is 1.83 and within the permissible error limits.

\section{Conclusions}

When the mobile signal travels through the wireless communication channel, it gets affected with the varying environment conditions of the wireless channel. So, to optimize these environment effects of transmitting channel this study used the response surface methodology. Details of input parameters whose effects were consider for optimization on received signal strength for LTE signal, their received optimized values, the best value of output response for these optimized input parameters and the inferences drawn from the work are as mentioned below.

- $\quad$ R.H (Relative Humidity), A.Q Index (Air Quality Index) for PM 2.5 particle, DBS (Distance from Base Station) and Temp (Temperature) were considered as input variables for the analysis of Received Signal Strength for LTE technology.

- Optimum conditions were obtained when environment parameters Temp (atmosphere temperature), R.H (Relative Humidity), A.Q Index - (Air Quality Index) for PM2.5 and DBS (Distance from Base Station) were found to be $13.10^{\circ} \mathrm{C}$, $31.30 \%, 52.10$ and $98 \mathrm{~m}$ respectively.

- Received Signal Strength for LTE (RSSLTE) was found to be $-87.0393 \mathrm{dBm}$.

- Desirability obtained from this model is unity and it indicates that this mathematical model satisfies all the practical requirements.

- $\mathrm{R}^{2}$ and $\mathrm{R}^{2}$ (adj) values obtained for received signal strength for LTE signals are $98.16 \%$ and $97.88 \%$ respectively and it was found quite satisfactory as it was obtained for more than $95 \%$ of the samples.

- Distance from the base station have the major effect on received signal strength for LTE signals as compared to other three input parameters which were considered for this research work.

- Optimized RSM results were validated though the confirmation trial. The error between actual and predicted was found to be within the range of $5 \%$.

With the use of response surface methodology, mathematical modeling and optimization of received signal strength for LTE signal could be done and that too with minimum number of experiments runs. RSM can be used for any application. After this study it is clear that with all these optimized values of input parameters, best possible value of Received Signal Strength for LTE Technology can be obtained.

\section{Nomenclature}

DBS Distance from Base Station

Temp Temperature

A. $Q$ Index Air Quality Index

RSSLTE Received Signal Strength for Long Term Evolution

RSL Received Signal Level

R.H Relative Humidity

RSS Received Signal Strength

$C C R D$ Central composite rotating design

LTE Long Term Evolution 
RSM Response Surface Methodology

UHF Ultra-High Frequency

VHF Very High Frequency

DTTBS Digital Terrestrial Television Base Stations

SHF Super High Frequency

\section{References}

1) Lo Sciuto, G., "Air pollution effects on the intensity of received signal in $3 \mathrm{G} / 4 \mathrm{G}$ mobile terminal," Int $J$ Energy Environ Eng , 10 221-229 (2019).

2) Danial Abdorahimi and Ali M. Sadeghioon, "Review-Comparison of Radio Frequency Path Loss Models in Soil for Wireless Underground Sensor Networks," J. Sens. Actuator Netw., 8(2) 35 (2019).

3) Sharifah Nurul Aisyah Syed Zafar, Nor Hazmin Sabri, Roslan Umar \& Zainol Abidin Ibrahim, "Radio Frequency Interference on Nearby Radio Astronomical Lines: Relationship between Wind Speed and Radio Signal Strength Measured at East Coast of Peninsular Malaysia," Sains Malaysiana, 48(1) 183-189 (2019).

4) A. S. Adewumi and O. Olabisi, "Characterization and Modeling of Vegetation Effects on UHF Propagation through a Long-Forested Channel," Progress In Electromagnetics Research Letters, 73 9-16 (2018).

5) N. R. Leonor, R. F. S. Caldeirinha, T. R. Fernandes, D. Ferreira and M. G. Sánchez, "A 2D Ray-Tracing Based Model for Micro- and Millimeter-Wave Propagation Through Vegetation," IEEE Transactions on Antennas and Propagation, 62(12) 6443-6453 (2014).

6) S. Hossein Mortazavi, Mohammad Salehe, M.H. MacGregor, "Maximum WSN coverage in environments of heterogeneous path loss", International Journal of Sensor Networks, 16(3) 185 - 198 (2014).

7) Fachransjah Aliunir, Teuku Yuri M. Zagloel, and Romadhani Ardi, "Discrete-Event Simulation and Optimization of Spare Parts Inventory and Preventive Maintenance Integration Model Considering Cooling Down and Machine Dismantling Time Factor," EVERGREEN Joint Journal of Novel Carbon Resource Sciences \& Green Asia Strategy, 07 79-85 (2020).

8) Raymond Kwan and Cyril Leung, "A Survey of Scheduling and Interference Mitigation in LTE," Hindawi Publishing Corporation, Journal of Electrical and Computer Engineering, 2010, Article ID 273486, 10 pages

9) J. C. Silva, G. L. Siqueira, P. V. G. Castellanos, "Propagation Model for Path Loss Through Vegetated Environments at $700-800 \mathrm{MHz}$ Band," Journal of
Microwaves, Optoelectronics and Electromagnetic Applications, 17(1) (2018).

10) M. V. S. N. Prasad, P. K. Dalela, and C. Misra, "Experimental Investigation of GSM $900 \mathrm{MHz}$ Results Over Northern India with Awas Electromagnetic Code and Other Prediction Models," Progress In Electromagnetics Research, 125 559-581 (2012).

11) Suliman, S. H., Hashim, W., Ismail, A. F., Zakariya, M. A., Yahya, A. S., \& Sauti, M. S., "Measurements of mobile signal received power level at Ringlet, Cameron Highland, Malaysia," International Journal of Engineering and Technology (UAE), 7(4) 404-409 (2018).

12) Myo Z.M., Mon M.T., "Analysis of Signal Variation Based on Path Loss in LTE Network," Genetic and Evolutionary Computing. Advances in Intelligent Systems and Computing Springer, 387 209-218 (2016) https://doi.org/10.1007/978-3-319-23204-1_21

13) Adegboyega Gabriel Adisa, "Refractivity Variation Effect on Radio Wave Propagation," International Journal of Science and Research (IJSR), 4(6) (2015).

14) Agbo, E.P., Ettah, E.B. \& Eno, E.E., "The impacts of meteorological parameters on the seasonal, monthly, and annual variation of radio refractivity," Indian $J$ Phys, 2020.

15) J. I. Iloke, F. A. Kamgba, N. A. Akonjom, "Comparative Analysis of Tropospheric Radio Refractivity during Rainy Season in Calabar, Nigeria," International Journal for Research in Applied Science \& Engineering Technology (IJRASET), 8(1) 391-393 (2020).

16) S. Fang and Y. S. Yang, "The Impact of Weather Condition on Radio-Based Distance Estimation: A Case Study in GSM Networks with Mobile Measurements," IEEE Transactions on Vehicular Technology, 65(8) 6444-6453 (2016).

17) Chima, A.I ,Oniya, A.I and Udegbe, S.U, “ Effects of Atmospheric Temperature and Wind Speed on Uhf Radio Signal; a Case Study of ESUT Community and Its Environs in Enugu State," IOSR-Journal of Applied Physics, 10(2) 83-90 (2019).

18) Joseph Amajama "Impact of Weather Components on (UHF) Radio Signal," International Journal of Engineering Research and General Science, 4(3) (2016).

19) J. Luomala and I. Hakala, "Effects of temperature and humidity on radio signal strength in outdoor wireless sensor networks," 2015 Federated Conference on Computer Science and Information Systems (FedCSIS), Lodz, 1247-1255 (2015).

20) S. Fang, Y. Cheng and Y. Chien, "Exploiting Sensed Radio Strength and Precipitation for Improved Distance Estimation," IEEE Sensors Journal, 18(16) 6863-6873 (2018). 
21) F. Beritelli, G. Capizzi, G. Lo Sciuto, C. Napoli and F. Scaglione, "Rainfall Estimation Based on the Intensity of the Received Signal in a LTE/4G Mobile Terminal by Using a Probabilistic Neural Network," IEEE Access, 6 30865-30873 (2018).

22) I. Shayea, T. Abd. Rahman, M. Hadri Azmi and M. R. Islam, "Real Measurement Study for Rain Rate and Rain Attenuation Conducted Over $26 \mathrm{GHz}$ Microwave 5G Link System in Malaysia," IEEE Access, 6 19044-19064 (2018).

23) Ryan Imansyah, " Impact of Internet Penetration for the Economic Growth of Indonesia," EVERGREEN Joint Journal of Novel Carbon Resource Sciences \& Green Asia Strategy, 5(2) 36-43 (2018).

24) Shashi Prakash Dwivedi, Nagendra Kumar Maurya, Manish Maurya, "Assessment of Hardness on AA2014/Eggshell Composite Produced Via Electromagnetic Stir casting Method," EVERGREEN Joint Journal of Novel Carbon Resource Sciences \& Green Asia Strategy, 6(4) 284-294 (2019).

25) Abhishek Sharma, Yashvir Singh, Nishant Kumar Singh, Amneesh Singla, Hwai Chyuan Ong, Wei-Hsin Chen, "Effective utilization of tobacco (Nicotiana Tabaccum) for biodiesel production and its application on diesel engine using response surface methodology approach," Fuel Elsevier (2020).

26) Shilpa Choudhary, Abhishek Sharma, Kashish Srivastava, Hemant Purohit, Mudita Vats, " Read Range Optimization of Low Frequency RFID System in Hostile Environmental Conditions by Using RSM Approach," EVERGREEN Joint Journal of Novel Carbon Resource Sciences \& Green Asia Strategy, 7(3) 396-403 (2020).

27) Karthik Vasudeva, Ozgur Ozdemir, Sugan R.S. Chandar, FatihErden, IsmailGuvenc, "Vehicular LTE Connectivity Analysis in Urban and Rural Environments using USRP Measurements," ARRAY, (2020).

28) A.Akinbolati, M.O.Ajewole, "Investigation of path loss and modeling for digital terrestrial television over Nigeria," Heliyon, 6(6) (2020). 